\title{
LIMITES E DESAFIOS NA GESTÃO DE RECURSOS HÍDRICOS POR COMITÊS DE BACIAS HIDROGRÁFICAS: UM ESTUDO NOS ESTADOS DO NORDESTE DO BRASIL $^{1}$
}

\author{
José Luciano Mendonça Morais ${ }^{2}$ \\ Élvia Fadul ${ }^{3}$ \\ Lucas Santos Cerqueira ${ }^{4}$
}

http://dx.doi.org/10.1590/1413-2311.187.67528

\section{RESUMO}

Esse artigo trata do processo de implementação da gestão de recursos hídricos por comitês de bacias hidrográficas, identificando fatores que interferem nesse processo. O estudo baseia-se nos pilares fundamentais sobre os quais se assenta esta gestão, que são a integração, a descentralização e a participação, utilizando, como indicadores de análise da sua efetividade, fatores técnicos, políticos e financeiros. A estratégia de investigação escolhida foi a de estudo de múltiplos casos. Os procedimentos metodológicos consistiram, inicialmente, na seleção dos casos e o levantamento dos dados primários ocorreu mediante observação direta, na participação em eventos e encontros da área observando e analisando os temas das discussões realizadas e na participação em reuniões de comitês de bacias. A pesquisa foi realizada em quatorze comitês de bacias de domínio estadual existentes nos estados do nordeste do Brasil. Os resultados mostram que o modelo foi idealizado para funcionar de forma autônoma, mas os comitês ainda não adquiriram esta autonomia. São os recursos oriundos da cobrança pelo uso da água que lhes darão condições para que eles se desenvolvam sem depender dos governos dos estados, nem financeiramente, nem politicamente. Entretanto, como a cobrança pelo uso da água é condição indispensável para a sustentabilidade financeira e, em

\footnotetext{
${ }^{1}$ Recebido em 01/09/2016, aprovado em 02/01/2018

${ }^{2}$ Instituto Federal de Sergipe (Brasil) - moraisj@bol.com.br

${ }^{3}$ UNIFACS (Brasil) - elvia@ufba.br

${ }^{4}$ Universidade Federal do Rio Grande (Brasil) - lucasscerqueira@gmail.com
} 
consequência, autonomia, e como esta cobrança ainda não foi instituída nesses comitês, esta autonomia fica impossível de ser exercida.

Palavras-chave: Recursos Hídricos. Comitês de Bacias. Descentralização. Participação.

\author{
LIMITS AND CHALLENGES IN WATER RESOURCES MANAGEMENT \\ BYRIVER BASIN COMMITTEES: A STUDY IN THE NORTHEAST OF BRAZIL
}

\begin{abstract}
This article focuses on the process of implementation of water management by hydrographic basin committees, identifying factors that influence its development. The study was based on the fundamental pillars on which settles this management, which are the integration, decentralization and participation, using as indicators of analysis, technical, political and financial factors that interfere with their effectiveness. The research strategy chosen was the study of multiple cases. The methodological procedures consisted, initially, in the selection of cases and the survey of the primary data occurred through direct observation, on participation in events and meetings in the area observing and analyzing the topics of discussions and participation in meetings of committees of basins. The results show that the model was designed to operate autonomously, but the committees haven't acquired this autonomy. Are the resources from charging for the use of water that give them conditions so that they develop without relying on the Governments of the Member States, neither financially nor politically. However, as the charges for the use of water is a prerequisite for financial sustainability and, as a result, autonomy, and how this collection has not yet been established in these committees, this autonomy is impossible to be exercised.
\end{abstract}

Key-words: Water Resources. Basin Committees. Decentralization. Participation.

\author{
LIMITES Y DESAFIOS EN LA GESTIÓN DE RECURSOS HÍDRICOS POR \\ COMITÉS DE BACIAS HIDROGRÁFICAS: UN ESTUDIO EN LOS ESTADOS DEL \\ NOROESTE DE BRASIL
}

\title{
RESUMEN
}


Este artículo trata del proceso de implementación de la gestión de recursos hídricos por comités de bacías hidrográficas, identificando factores que interfieren en este proceso. El estudio se basa en los pilares fundamentales sobre los cuales se fundamenta esta gestión, que son la integración, la descentralización y la participación, utilizando, como indicadores de análisis de su efectividad, factores técnicos, políticos y financieros. La estrategia de investigación elegida fue el estudio de casos múltiples. Los procedimientos metodológicos consistieron, inicialmente, en la selección de casos y el estudio de los datos primarios se produjo a través de observación directa, reuniones en la zona observando y analizando los temas de debate y participación en reuniones de los comités de cuencas. La investigación fue realizada en catorce comités de bacías de dominio estatal existentes en los estados del noroeste de Brasil. Los resultados muestran que el modelo fue diseñado para funcionar de manera autónoma, pero las comisiones no han adquirido esta autonomía. Son los recursos de cobro por el uso del agua que les dan las condiciones para que desarrolle sin depender de los gobiernos de los Estados miembros, ni económicamente ni políticamente. Sin embargo, como los cargos por el uso del agua es un requisito previo para la sostenibilidad financiera y, en consecuencia, autonomía, y cómo esta colección todavía no se ha establecido en estos comités, esta autonomía es imposible de ejercerse.

Palabras-clave: Recursos Hídricos. Comités de Bacías. Descentralización. Participación.

\section{INTRODUÇÃO}

A crise ambiental é uma realidade. E a água, elemento indispensável para a vida dos seres humanos, está no foco do embate entre o modelo de produção capitalista, que pressupõe o uso indiscriminado dos recursos (MÉZAROS, 2002), e a natureza, cuja condição é finita. Frente a isso, o neoliberalismo se estabeleceu nos últimos anos como uma política de desenvolvimento que exerce forte influência no capitalismo mundial e pressupõe a diminuição do papel Estado e a transferência dos ativos e serviços públicos para o setor privado, principalmente para as empresas transnacionais, impondo desafios emergentes aos países detentores de recursos que são atrativos ao capital, como a água e o saneamento, para exemplificar. Castro (2007) adverte que os processos de privatização da água na América Latina foram motivados e capitaneados pelas políticas neoliberais e menosprezam o processo 
histórico de universalização dos serviços de água na Europa através da ação decisiva do Estado.

Á água é um bem comum e inalienável. Contudo, dotada de valor econômico, passa a ter uma importância significativa como insumo produtivo na acumulação capitalista, passa a ter um valor de troca, como uma mercadoria (SANTOS, 2002; SANTOS, MORAES; ROSSI, 2013; FLORES; MISOCZKY, 2015), que pode ser transacionada em um mercado e a ser alvo de disputas em todo o globo. O Estado é o seu guardião universal, seu fiador perante toda a sociedade, seu regulador natural (RIO; MOURA; SALES, 2004) e a forma como gerencia a água também está em crise, pois a poluição e degradação avançam e nem toda população tem acesso à água potável e saneamento, como minimamente se espera.

O Estado tem por desafio estabelecer um modelo de governança que pressuponha garantir investimentos necessários para a preservação e a universalização da água, o envolvimento da sociedade no processo de cogestão, evitar a apropriação por agentes econômicos nacionais e estrangeiros de forma exclusiva e garantir os usos múltiplos da água. Diante desses desafios, nada modestos, e frente ao desafio de conciliar esta agenda de um projeto participativo e democratizante na gestão dos recursos hídricos no contexto neoliberal, o que Dagnino (2004) denomina como a Confluência Perversa, o Estado precisa contemplar uma gestão que garanta os investimentos necessários para a preservação da água para as gerações futuras e estabelecer resistência ao processo de privatização que se criva como solução mais eficiente.

Já a condição subalterna em que os países periféricos estão diante do capitalismo mundial e a consequente influência que agentes internacionais como o Banco Mundial, FMI e ONU exercem em suas políticas, afetam diretamente a adoção de modelos de governança que estão alinhados com essas entidades. Emergem modelos que preconizam a utilização de instrumentos econômicos como forma de regulação (FLORES, 2006, MARTINS, 2013).

Para Martins (2013), os instrumentos econômicos mais utilizados mundialmente estariam alinhados com a perspectiva de criação de um mercado de água e a valorização da água através da imposição da cobrança. $\mathrm{O}$ autor complementa que a ideia de mercado de água estaria assentada na base da teoria neoclássica do marginalismo na qual dentro de um livre mercado um bem escasso se autorregula.

Já a cobrança, seria um instrumento econômico que permitiria atribuir aos usuários e poluidores as responsabilidades pelas externalidades e impactos danosos que suas atividades provocariam na utilização da água (DINAR, 2000). A adoção da cobrança pelo uso 
dos recursos hídricos é com base no princípio do poluidor-pagador (SILVA; PRUSKI, 2000; SANTOS, 2002).

Cabe salientar que a adoção de um instrumento de cobrança pressupõe a incapacidade do Estado em estabelecer um controle eficiente e a suposição que um modelo econômico seria mais eficaz na gestão das águas (SANTOS; MORAES; ROSSI, 2013). Os recursos provenientes desse mecanismo atrairam a defesa de alguns ambientalistas (MARTINS, 2013; SANTOS; MORAES; ROSSI, 2013) na perspectiva de que a cobrança permitiria um uso racional da água (PORTO; PORTO, 2008; SILVA; PRUSKI, 2000) e a alocação de recursos para preservação das bacias (MARTINS, 2013).

O modelo brasileiro de gestão das águas é inspirado no modelo francês e pressupõe a gestão descentralizada, participativa e integrada (CAMPOS; FRACALANZA, 2010; SANTOS; MORAES; ROSSI, 2013), um avanço em relação ao modelo que privilegiava o setor elétrico e que vigorou por muito tempo no país. E como instrumento econômico utiliza a cobrança. Tal modelo está expresso na Lei $n^{\circ}$ 9.433/97, denominada de Lei das Águas, a Política Nacional de Recursos Hídricos (PNRH) que confere poder de gestão a grupos ligados a cada uma das principais bacias hidrográficas do país, criando os Comitês de Bacias Hidrográficas.

A análise em relação ao modelo de governança das águas no Brasil pressupõe, minimamente, três perspectivas: A primeira seria uma análise que questiona os fatores políticos, econômicos e sociais que envolvem a implementação do modelo de governança da forma como foi estabelecido na Lei das Águas, uma análise ex ante. Tal análise, que pode ser feita com base na abordagem teórica de autores como Karl Marx, István Mészáros, Hannah Arendt, David Harvey, Esteban Castro, Joachim Hirsch, permitiria o entendimento da relação complexa entre Estado, Sociedade e Natureza, e, de forma complementar, a discussão sobre a apropriação capitalista da água, da água como mercadoria, feitas por Santos (2002); Flores (2006); Santos, Moraes e Rossi (2013); Flores e Misoczky (2015) e da regulação de bens Coase (1991), Ostrom (2008), Hardin (1968) e Olson (1971).

A segunda perspectiva é uma análise crítica que questiona o atual modelo vigente quanto à sua capacidade de garantir o protagonismo do Estado na gestão das águas e a coparticipação da sociedade civil para universalizar o acesso da água, garantir os recursos necessários para a preservação da bacia e evitar a institucionalização de um mercado de águas como um modelo de regulação (SANTOS, 2002; MARTINS, 2003; DAGNINO, 2004; RIO; MOURA; SALES, 2004; SANTOS; MORAES; ROSSI, 2013; FLORES; MISOCZKY, 2015). A terceira, uma análise a partir do modelo implantado, ex post, pressupõe analisar os 
limites e os entraves que comprometem a efetividade do atual modelo de governança para garantir uma gestão descentralizada, participativa e a instituição da cobrança pelo uso da água (SILVA; PRUSKI, 2000; ABERS; JORGE, 2005; GUTIÉRREZ, 2006; JACOBI, 2006; PORTO; PORTO, 2008; CAMPOS; FRACALANZA, 2010; LANNA, 2010, LEMOS, 2011).

Este estudo está baseado na terceira perspectiva de análise, já que passados 20 anos da promulgação da Lei que criou este sistema, vários comitês ainda se encontram em uma fase inicial do processo de implementação, sem os instrumentos de gestão e sem a institucionalização da cobrança pelo uso da água, que poderiam garantir autonomia administrativa e financeira aos comitês (FADUL, 1999; GUTIÉRREZ, 2006). Grande parte dos comitês atualmente em funcionamento não tem sustentabilidade financeira, carece de apoio político e de capacitação para que seus membros possam dar cumprimento à sua missão institucional.

A complexidade que envolve a implementação desta política pública tem gerado algumas assimetrias no sistema, em âmbito nacional. Enquanto, por exemplo, o estado do Maranhão ainda não criou comitê algum, o estado de São Paulo conseguiu criar todos os comitês previstos para o seu território, inclusive em alguns destes já há arrecadação com a cobrança pelo uso da água.

Outro ponto que parece aumentar as assimetrias encontradas entre os comitês de bacia das várias regiões do Brasil é o envolvimento da comunidade em questões ligadas à água. Nas regiões com maior desenvolvimento, como a região sudeste, o envolvimento da comunidade é mais efetivo e provoca, como consequência, um melhor desempenho do modelo nesta região. As questões referentes à água estão na pauta do dia das discussões dessas comunidades. Pessoas altamente qualificadas se colocam à disposição para serem membros dos comitês de bacias, os prefeitos e ou outros dirigentes públicos sempre se fazem presentes nessas reuniões, alguns inclusive são membros e até eleitos presidentes dos comitês.

É esta constatação de descompassos no estágio de implementação do modelo de gestão de recursos hídricos nos diferentes estados da federação que justifica a necessidade e a relevância de esclarecer as razões e os fatores que influenciam estas variações, pois estas diferenças demonstram que pode estar havendo dificuldades na implementação desta política pública em algumas localidades do país. Assim, este trabalho consiste em identificar e analisar os fatores restritivos e propulsores que interferem na implementação do atual modelo da gestão de recursos hídricos por comitês de bacias hidrográficas nos estados do nordeste. Paralelamente, e de forma complementar, foi também verificado entre os comitês 
pesquisados, qual o entendimento destes com relação ao modelo e à sua efetividade.

O estudo envolve uma análise da situação em que se encontram os comitês de bacias de domínio estadual, localizados nos estados da Bahia, Sergipe, Alagoas, Pernambuco, Paraíba, Rio Grande do Norte, Ceará e Piauí, identificando os principais avanços alcançados e os fatores que limitam o seu desenvolvimento. O estado do Maranhão não foi alvo direto desta pesquisa por saber-se, antecipadamente, que não existia comitê algum instalado neste estado, o que já constituiu, também, um resultado deste estudo. A pesquisa foi realizada em quatorze comitês de bacias existentes nos estados do nordeste, mostrando que vários desses comitês ainda não atingiram o estágio de funcionamento conforme preconizado pela lei que os criou.

Este artigo está organizado em seis partes, iniciando com este capítulo introdutório, que traz a contextualização, o problema em estudo, os objetivos da pesquisa e a sua justificativa. Em seguida o artigo trata da Lei das Águas apresentando os fundamentos e instrumentos da Política Nacional de Recursos Hídricos, e destacando as bases em que foram criados os comitês de bacias hidrográficas. Como fundamento conceitual para embasar as análises o estudo traz uma discussão acerca dos processos de descentralização e participação que envolvem a estruturação e o funcionamento desses comitês, indicando os elementos sobre os quais se assentaram as análises. Apresenta, em seguida, os procedimentos metodológicos utilizados, os resultados e análises e, por fim, as conclusões.

\section{A LEI dAS ÁGUAS E A CRIAÇÃo dOS COMITÊS DE BACIAS HIDROGRÁFICAS}

Em 1991 o governo federal encaminhou ao Congresso Nacional a proposta para a criação do Sistema Nacional de Gerenciamento de Recursos Hídricos - SINGREH, que levou seis anos tramitando no congresso, sendo a lei sancionada somente em janeiro de 1997 (Novaes, 2006). É no final da década de 90 que a Lei no $9433 / 97$ vem dar nova versão à gestão de recursos hídricos no país. Esta lei, que institui a política nacional e trata do sistema de gerenciamento nacional dos recursos hídricos, passa a ser o marco balizador para a questão das águas, definindo instrumentos, níveis, atores e organismos envolvidos no sistema nacional de gerenciamento, como se pode verificar no seu artigo 33.

O sistema é composto pelo Conselho Nacional de Recursos Hídricos - CNRH criado em 1998, o órgão máximo do SINGREH e principal fórum nacional de discussão sobre a gestão de recursos hídricos do país, de caráter deliberativo, atuando através de 
moções e resoluções. A Agência Nacional de Águas - ANA, criada pela Lei n 9.984/00, como autarquia especial ligada ao Ministério do Meio Ambiente - MMA é um órgão operacional do SINGREH com o objetivo principal de implementar a PNRH, em articulação com os órgãos públicos e privados integrantes do sistema. Ainda compondo o sistema há os Conselhos Estaduais e o do Distrito Federal com diferentes âmbitos de atuação, compreendendo os rios de domínio dos estados e do Distrito Federal, e contando com a participação de representantes dos municípios. Finalmente encontram-se os Comitês de Bacias Hidrográficas, base do SINGREH, também conhecidos como "Parlamento das Águas". São órgãos colegiados, consultivos e deliberativos, e podem ser constituídos em bacias de rios de domínio estadual ou federal. Em sua composição estão às representações da sociedade civil organizada, dos setores usuários da água e do poder público. As Agências de Bacias, ou Agências de Água, são as entidades criadas para dar apoio administrativo, técnico e financeiro a esses comitês de bacias hidrográficas. Cabe às agências colocar em prática as ações, planos e projetos previamente aprovados pelo Comitê, inclusive a cobrança pelo uso da água.

Como fundamentos deste modelo encontram-se a gestão integrada, descentralizada e participativa e a cobrança pelo uso da água. Além do Governo federal e estadual, foram incorporados à gestão dos recursos hídricos representantes do poder municipal, dos usuários da água e da sociedade civil que passaram a integrá-la a partir da criação de dois entes públicos, os comitês de bacia hidrográfica e as agências de bacia.

A integração é encontrada tanto verticalmente, entre os níveis federal, estadual, municipal e mesmo local, como horizontalmente, realizada entre os vários usos da água, os usos e ocupação do solo, os vários segmentos da sociedade e a intersecção do setor dos recursos hídricos e do meio-ambiente. A descentralização ocorre, quando se considera a bacia hidrográfica como a unidade territorial para implementação da política através de seu Comitê de Bacia Hidrográfica. A participação ocorre justamente na constituição do comitê e no seu funcionamento interno, e isso faz com que as decisões sejam tomadas na instância mais próxima dos interessados.

As exigências de uma gestão aberta, transparente e participativa, vieram, assim, em um discurso de modernização, como instrumento essencial para a legitimação e garantia de eficiência dessas políticas públicas em uma espécie de tendência mundial. Os países em desenvolvimento começaram a incorporar na sua legislação esta filosofia. É o que se observa, por exemplo, na Lei de Gestão Ambiental da Água da Ciudad Autónoma de Buenos Aires, na Argentina: 
Cada Estado Provincial es responsable de la gestión de sus propios recursos hídricos y de la gestión coordinada con otras jurisdicciones cuando se trate de un recurso hídrico compartido. La descentralización de funciones debe alcanzar el nivel local más próximo al usuario del agua que resulte apropiado, promoviendo la participación de organizaciones comunitarias en la gestión del agua. Al mismo tiempo se fomenta la participación efectiva de toda la sociedad en la definición de los objetivos de la planificación hídrica, en el proceso de toma de decisiones y en el control de la gestió. (ARGENTINA, 2010, Ley no 3.295/00, item 16).

A água, apesar de ser um bem comum, passou a ter um valor econômico, tornando-se possível a cobrança pelo seu uso, como um meio de promover o uso racional e gerar recursos para investimentos na própria bacia hidrográfica em que foram captados os recursos. A determinação do preço e a aplicação dos recursos adquiridos a partir da cobrança pelo uso da água são de responsabilidade dos comitês. Este instrumento "Além de ser o principal meio de gerar recursos para a gestão da água em cada bacia, a cobrança seria a chave para a sustentabilidade de um novo sistema decisório descentralizado e participativo" (ABERS; JORGE, 2005, p. 2).

Com isso a lei buscou assegurar viabilidade financeira, ao destinar os recursos arrecadados com a cobrança pelo uso da água ao custeio dos organismos que integram o sistema e à constituição dos financiamentos das intervenções identificadas pelo processo de planejamento, assim como assegurar a viabilidade administrativa, ao criar organismos de apoio técnico, financeiro e administrativo aos colegiados do Sistema - as Agências de Água e a Secretaria Executiva.

Com a promulgação da "Lei das Águas", seguindo uma tendência mundial de considerar a bacia como unidade de planejamento e implantação da PNRH, o Brasil adota o modelo de bacia hidrográfica, e a gestão da água passa a ter essas bacias como âmbito territorial e não as fronteiras administrativas e políticas dos entes federados. A maioria das políticas ambientais também adota a bacia hidrográfica como unidade territorial de planejamento e implantação.

O poder de gestão passa a ser dos grupos ligados a cada uma das principais bacias hidrográficas, integrando os comitês, representantes dos segmentos: público, privado, não 
governamental, usuários e outros grupos da sociedade civil. São os comitês que vão realizar a gestão participativa e descentralizada dos recursos hídricos em um determinado território, utilizando instrumentos técnicos de gestão, da negociação de conflitos e da promoção dos usos múltiplos da água.

Ao implementar este modelo o governo federal estabelece também a descentralização do poder de decisão, integrando as ações públicas com as privadas. Com a descentralização a responsabilidade pela tomada de decisão passa para os governos regionais e locais, retirando-se do Distrito Federal e das capitais estaduais essa prerrogativa.

Dentro de um contexto mais amplo de revisão das atribuições do Estado, do papel dos usuários e do próprio uso da água, “a legislação propõe uma política participativa e um processo decisório aos diferentes atores sociais vinculados ao uso da água. O modelo é inovador, tanto no Brasil como mundialmente. Com ele ocorre o rompimento das práticas "profundamente arraigadas de planejamento tecnocrático e autoritário, devolvendo poder para as instituições descentralizadas de bacia" (JACOBI, 2006, p. 212). A descentralização proposta está relacionada com a distribuição do poder e de território tendo como objetivo gerar mais democracia, mais eficácia, mais justiça social (JACOBI, 2000).

Para cumprir seu papel, os comitês obedecem à seguinte estrutura: cada comitê de bacia tem seu próprio estatuto, no qual são definidas as regras e procedimentos para realização das assembleias deliberativas, as formas de participação, de eleição e as competências. Todo e qualquer cidadão pode participar. As assembleias são públicas e os representantes eleitos para compor o colegiado como titulares e suplentes, têm poder de voto. Os mandatos de todos os integrantes são de dois anos e todos podem se candidatar aos cargos da diretoria e câmaras técnicas, respeitando sempre a característica tripartite.

Segundo Tucci (2001, p. 90), a Lei $\mathrm{n}^{0}$ 9.433/97 foi resultado de um longo processo de avaliação das experiências de gestão de recursos hídricos e de formulação de propostas para a melhoria dessa gestão no país. O autor considera que

[...] o sistema criado se sobrepõe, mas não se opõe, à estrutura administrativa existente. A Lei mantém as competências dos organismos existentes e potencializa sua atuação. Cria somente os organismos necessários à execução das novas atividades, as quais, por terem base territorial diversa da divisão político-administrativa do país, não poderiam ser exercidas pelos organismos existentes, que têm base municipal, estadual ou federal. As Agências de Água têm 
como área de atuação uma ou mais bacias hidrográficas e suas competências primordiais são o planejamento dos recursos hídricos da bacia e a cobrança pelo uso da água.

A Figura 1 apresenta as funções dos comitês de bacia conforme preconizadas pela Lei $n^{\circ} 9.433 / 97$.

Figura 1 - Funções dos comitês de bacia

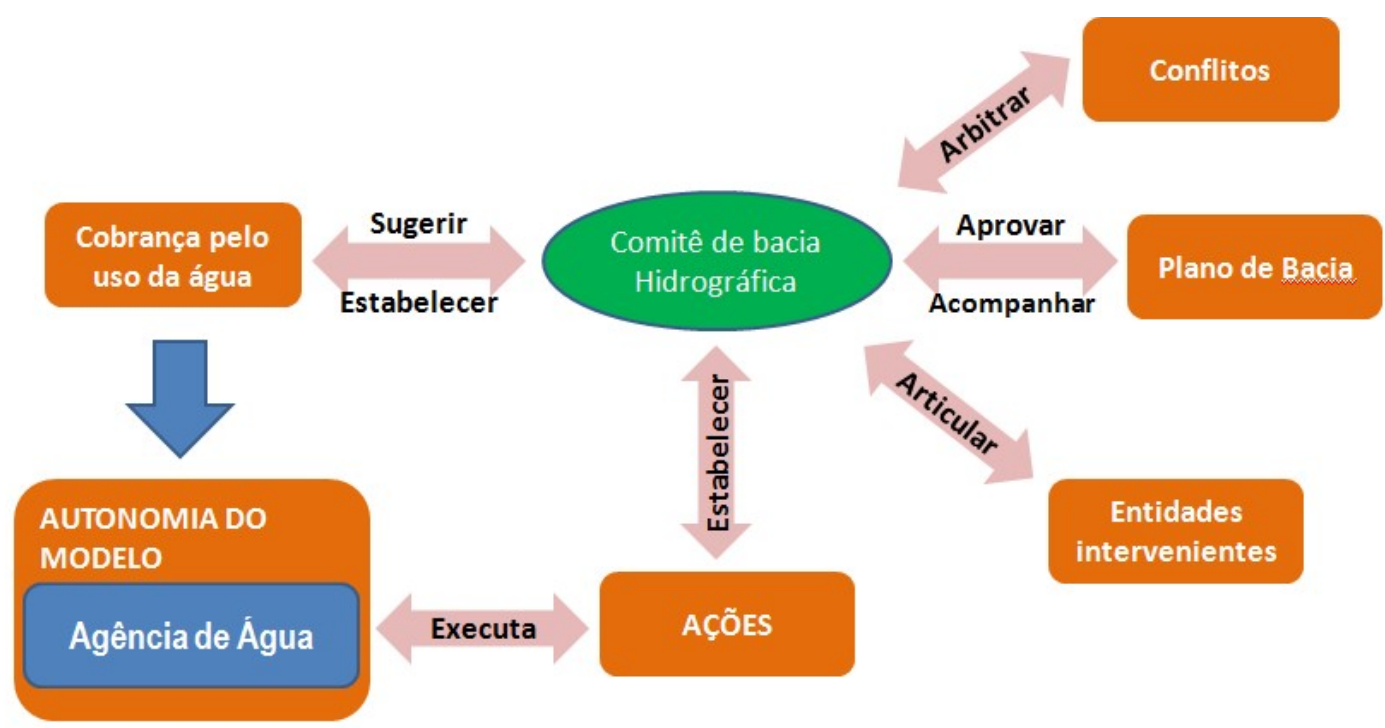

Fonte: elaborado pelos autores com base na Lei $n^{\circ}$ 9.433/97.

\section{A MUdANÇA DE PARAdIGMAS NA GESTÃo dAS ÁGUAS: FUNDAMENTOS DO NOVO MODELO}

Estudo realizado por Fadul et al. (2012) acerca da produção científica sobre gestão de recursos hídricos e de como tem ocorrido a sua evolução, a fim de estabelecer possíveis direcionamentos de investigação, constata que, apesar dos debates em torno da água terem se ampliado com discussões sobre várias questões, levantamentos, análises e discussões sobre este novo modelo de gestão ainda não fazem parte das agendas de pesquisas. Há estudos que identificam experiências empíricas de êxitos e acertos ou evidenciem lacunas e dificuldades encontradas na implementação deste novo modelo de gestão, mas o tema carece de discussões mais acadêmicas. Esta situação faz com que não existam trabalhos teóricos mais aprofundados, que permitam subsidiar outras pesquisas e que sirvam de base 
para a compreensão de um fenômeno social relativamente novo que é a gestão de recursos hídricos por comitês de bacias hidrográficas.

Com esta constatação, para este estudo dos comitês de bacia do nordeste buscouse identificar dimensões de análise e criar indicadores que pudessem trazer alguns elementos de compreensão para o entendimento da situação atual desses comitês. Essas dimensões de análise são, sem dúvida, os pilares fundamentais sobre os quais se assenta este modelo de gestão que são a descentralização e a participação da sociedade com poder de decisão. Sobre esses dois conceitos é possível encontrar estudos que discutem essas duas questões do ponto de vista conceitual e identificar marcos que delineiem pesquisas, mas ainda assim, com pouca aplicação sobre os comitês de bacias.

Com relação à descentralização no setor de recursos hídricos há estudos que apontam a existência de aspectos positivos e, também, de aspectos negativos, na aplicação desse princípio. Há autores que defendem a descentralização do ponto de vista da redução de custos de transação ou como um mecanismo de democratização (AGRAWAL; RIBOT, 2000; CAMPBELL, 2003; TENDLER, 1997 Apud ABERS; JORGE, 2005), mas há também aqueles que questionam a sua efetividade pela falta de competência dos comitês na tomada de decisões e na execução das suas tarefas (AGRAWAL; RIBOT, 2000; ARRETCHE, 1996; BLAIR 2000; BRANNSTROM, 2004; RIBOT, 2002; MANOR, 1999 Apud ABERS; JORGE, 2005).

Com relação à dimensão participação também não há consenso entre os autores sobre os seus limites e as suas possibilidades. Apesar de os processos participativos terem ganhado espaço com a promulgação da Constituição de 1988, ainda podem ser considerados novos na cultura nacional.

Essas duas dimensões - descentralização e participação - são construções institucionais reais, são dados concretos que, a rigor, não podem ser alterados, visto que foram definidos por lei. Assim, até o momento presente, a gestão de recursos hídricos no país deverá ser feita por comitês de bacias hidrográficas, que são unidades descentralizadas do poder central, nacional e do subnacional, e devem funcionar em gestão colegiada e participativa, com poder de decisão. Desse modo, as análises dos comitês do nordeste podem, então, ser realizadas a partir da identificação, na literatura e na prática, de aspectos propulsores e restritivos que essas duas dimensões impõem à gestão desses comitês. Como esses dois pilares sobre os quais foi estabelecida a política nacional de recursos hídricos são elementos que deveriam assegurar a eficácia da implantação dos mecanismos desta política, eles vão afetar diretamente a implantação e o funcionamento do modelo de gestão. 
Nesse sentido, e à primeira vista, tanto na dimensão da descentralização, quanto na da participação, é possível perceber que as vantagens advindas desses dois elementos do modelo de gestão, envolvem elementos intangíveis, ou seja, podem trazer ganhos sociais mais amplos, mas que são mais difíceis de serem mensurados e analisados no curto prazo, no que tange ao seu impacto no processo efetivo de gestão. No entanto, quando se trata dos fatores dificultadores que essas duas dimensões têm provocado na gestão dos comitês, esses fatores são possíveis de serem verificados, tanto por meio de indicadores externos aos comitês, relacionados ao contexto e ao ambiente em que se situam, quanto por meio de indicadores internos à dinâmica do seu funcionamento, e podem afetar o desempenho adequado dos mesmos.

No entanto, apesar de essas construções institucionais terem sido estabelecidas para todos os comitês criados, o que se observa é que o grau de implementação dos comitês no país é diferenciado e ocorre com intensidades diferentes de acordo com a região. Assim, as experiências de implantação dos comitês de bacias hidrográficas na região nordeste podem ser consideradas iniciativas inovadoras, mas não têm se constituído em experiências bem sucedidas de gestão. Mesmo considerando que há, nesse modelo, contradições internas e externas, e algumas limitações, as dimensões descentralização e participação, isoladas, podem evidenciar essas lacunas e possibilidades, mas não são suficientes para explicar essas diferenças regionais.

Para se identificar e isolar as razões do insucesso do modelo em alguns estados ou regiões, pois a diversidade de aspectos e a dinâmica que perpassa esse processo são muito amplas, é preciso um esforço criterioso de sistematização e de interpretação dessa realidade. Esse esforço foi feito a partir de duas perspectivas. Uma perspectiva encontrada em Fadul (1999) quando a autora analisa a experiência de orçamento participativo na cidade de Salvador, e a outra, encontrada em Gutiérrez (2006) quando o autor faz um estudo do caso do funcionamento do Comitê da Bacia Hidrográfica do Rio Gravataí.

Utilizando a abordagem de Fadul (1999), percebe-se que o processo de instalação e operacionalização desses comitês vai sofrer interferência de fatores restritivos internos ao próprio processo de implementação, mas também, relativos ao contexto no qual ele se processa. Como fatores restritivos internos a autora se refere a fatores de caráter institucional, financeiro, administrativo, socioeconômico e político, levando em conta, também, a competência técnica.

Nessa mesma linha de raciocínio e analisando o processo de reforma na gestão de recursos hídricos desenvolvido no país, focando na criação e na dinâmica de funcionamento 
do Comitê Gravataí, Gutiérrez (2006) considera que para garantir a viabilidade de políticas públicas participativas o primeiro passo a ser dado é conseguir a interação e colaboração entre atores estatais e atores sociais, mas somente isso não garante que essas políticas produzam resultados de modo eficiente. Continuando a sua argumentação, o autor afirma que

[...] para sobreviver e cumprir minimamente com os seus objetivos, um foro de gestão participativa como o Comitê Gravataí tem de superar sérios problemas em relação à sua sustentabilidade técnica, financeira e política. [...]

Garantir a sustentabilidade nessas três dimensões será fundamental para que o Comitê Gravataí, assim como qualquer outro comitê, possa cumprir com os seus objetivos declarados, isto é, empreender estudos e projetos que garantam o uso eficiente, a recuperação e a conservação dos recursos hídricos da bacia (GUTIÉRREZ, 2006, p. 82 e 105).

Incorporando a perspectiva encontrada em Fadul (1999) e utilizando o tripé definido por Gutiérrez (2006) no seu estudo como fontes de inspiração, foi estruturado o modelo de análise para o presente estudo o qual foi empregado para a realização da pesquisa feita em quatorze comitês de bacias existentes nos estados do nordeste. Para fins deste artigo foram utilizados apenas indicadores internos que permitiram analisar os fatores restritivos e propulsores que afetam o desempenho dos comitês, de forma a entender as razões das variações no estágio de implementação do modelo de gestão de recursos hídricos nos diferentes estados e destacar os fatores que influenciam estas variações.

São eles: fatores técnicos, envolvendo a capacidade técnica dos participantes, seu engajamento e a sua capacitação para a gestão participativa; fatores políticos, envolvendo a relação com os outros segmentos que compõem o Sistema Nacional de Recursos Hídricos, apoio do poder público às decisões, atuação dos stakeholders, envolvimento da sociedade com a questão; e os fatores financeiros, envolvendo recursos captados pela cobrança recursos transferidos pelo poder público, outras fontes de financiamento.

Do ponto de vista de Gutiérrez (2006, p. 105), sustentabilidade técnica significa que uma decisão participativa e democrática carece de uma sólida base técnica. Diz ele que “distintas questões até agora discutidas pelo Comitê Gravataí demonstram como, desde a 
própria ótica dos atores envolvidos, uma decisão perfeitamente participativa e democrática carece, ademais, de uma sólida base técnica" (GUTIÉRREZ, 2006, p. 105). O autor argumenta que para se obter uma decisão perfeitamente participativa e democrática é fundamental que exista uma sólida base técnica. "A discussão sobre a construção de uma barragem tem sido fortemente mediada pelo conhecimento tecnológico" (GUTIÉRREZ, 2006, p.15). Se não existir esta base sólida pode-se gerar uma decisão perfeitamente participativa e democrática, porém insustentável do ponto de vista técnico. Para o autor, a Agência de Bacia é uma peça fundamental para evitar que ocorra este tipo de situação, pois a mesma têm por função assistir operativa e tecnicamente os comitês na implementação das suas decisões, tanto na promoção de cursos de capacitação para seus membros com na contratação de empresas especializadas para assessoramento.

Com relação a este aspecto, discutindo os processos relativos aos orçamentos participativos Fadul (1999, p. 155) já apontava a dimensão técnica como um dos fatores restritivos ou dificultadores inerentes a tais processos. A autora afirma que

A criação de espaços institucionais de participação com maior atenção às demandas populares envolve uma dimensão técnica. Os mecanismos e instrumentos que viabilizam a cooperação, a negociação e a busca do consenso são os recursos humanos e técnicos dos governos locais e, em geral, a dimensão técnica tende a sobrepujar, necessariamente, a manifestação popular, posto que as propostas têm que passar por uma análise de viabilidade que pode desvirtuar as solicitações originais.

De todo modo, mesmo estando a dimensão técnica equacionada é necessária decisão política que só poderá ser viabilizada pelo comitê havendo disponibilidade financeira. Com relação à sustentabilidade financeira, Gutiérrez (2006) considera imprescindível que o processo da cobrança de preços públicos pelo uso da água seja iniciado, e para isso, mais uma vez, é necessária à existência da Agência de Bacia. Os recursos oriundos desta cobrança têm a finalidade de garantir a autonomia dos comitês, o qual deve alocar recursos para ações e projetos a serem executados em suas respectivas bacias, aprovados no comitê, além de cobrir os gastos operativos. Argumenta, ainda, que os problemas de sustentabilidade técnica e de sustentabilidade financeira remetem à falta de apoio ou aval político para investir na criação de agências. 
Quanto à sustentabilidade política, Gutiérrez (2006) destaca a necessidade de apoio político para executar as decisões tomadas pelos comitês para executarem seus planos e garantir a sua legitimidade. A falta de sustentabilidade política pode estar sendo provocada por restrições orçamentárias dos governos. Com as restrições orçamentárias, outros setores têm recebido maior atenção dos governos que deixa a questão da água em segundo plano. Pode estar havendo, também, um entendimento equivocado do que seria a cobrança pelo uso da água, a qual muitos consideram um novo tributo e, consequentemente, uma ação impopular.

Ainda que tenha sido possível isolar alguns indicadores induzidos pela experiência, construídos através de deduções e analogias, e a partir da lógica de relações entre os elementos desse sistema, não é difícil perceber, em última instancia, que a análise dos comitês de bacia, necessariamente, transcende o próprio comitê, não se limitando apenas ao que ocorre no seu âmbito. Como bem afirma Fadul (1999, p. 153),

Em qualquer circunstância, os fatores que determinam o sucesso ou insucesso da implantação de determinadas políticas públicas são múltiplos. Podem estar contidos no próprio processo institucional, administrativo e financeiro de sua implementação traduzido nas práticas dos atores, podem emergir do contexto político e socioeconômico onde a experiência ocorre como podem, também, ser externos ao processo, situando-se num âmbito histórico mais amplo.

Nesse espaço de relações no qual se constitui um comitê de bacia, onde transitam, se interpõem e se opõem interesses conflitantes da sociedade, dos setores do poder público e de instâncias de poder, a lógica que rege o seu funcionamento e que pode interferir na sua efetividade vai além do que pode ser observado no interior do próprio comitê. Ao implantar este modelo no Brasil, além de todas as determinações jurídicas e legais conferidas pela legislação, adaptações à cultura política e administrativa teriam que ser feitas, considerandose, inclusive, as diferenças regionais.

\section{PROCEDIMENTOS METODOLÓGICOS}

O objetivo desse estudo foi analisar os fatores restritivos e propulsores na 
implementação do atual modelo de gestão de recursos hídricos por comitês de bacias hidrográficas nos estados do nordeste, através de uma pesquisa qualitativa. A estratégia de investigação escolhida foi a de estudo de múltiplos casos. No quadro 01 é possível verificar as dimensões e indicadores representados no modelo de análise para essa pesquisa.

Quadro 1- Modelo de análise

\begin{tabular}{|c|c|c|}
\hline Conceitos & Dimensões & Focos de análise \\
\hline \multirow{11}{*}{$\begin{array}{c}\text { Fatores } \\
\text { Condicionantes da } \\
\text { Gestão de Recursos } \\
\text { Hídricos por } \\
\text { Comitês de Bacias } \\
\text { Hidrográficas }\end{array}$} & \multirow{4}{*}{ Fatores Técnicos } & Capacidade técnica dos participantes \\
\hline & & Capacidade de argumentação \\
\hline & & Motivação dos participantes (Engajamento) \\
\hline & & $\begin{array}{l}\text { Promoção de cursos pelo comitê para capacitar os } \\
\text { membros }\end{array}$ \\
\hline & \multirow{4}{*}{ Fatores Políticos } & $\begin{array}{l}\text { Relação com os outros segmentos que compõem o } \\
\text { Sistema Nacional de Recursos Hídricos (ANA, } \\
\text { Conselhos etc.) }\end{array}$ \\
\hline & & Apoio do poder público às decisões \\
\hline & & Atuação dos Stakeholders \\
\hline & & Envolvimento da sociedade \\
\hline & \multirow{3}{*}{$\begin{array}{l}\text { Fatores } \\
\text { Financeiros }\end{array}$} & Recursos capitados pela cobrança \\
\hline & & Recursos transferidos pelo poder público \\
\hline & & Outras fontes de financiamento \\
\hline
\end{tabular}

Fonte: elaborado pelos autores.

Os procedimentos metodológicos consistiram, inicialmente, na seleção dos casos e o levantamento dos dados primários ocorreu mediante observação direta, na participação em eventos e encontros da área observando e analisando os temas das discussões realizadas e na participação em reuniões de comitês de bacias: dos Comitês da Bacia do Recôncavo Norte e Inhambupe em Salvador, Bahia e do Comitê da Bacia do Rio Sergipe em Laranjeiras, Sergipe. Em seguida foram realizadas entrevistas em órgãos ambientais dos governos 
estaduais com responsáveis pela implementação da política de recursos hídricos, em todos os estados do nordeste, com exceção do Maranhão por saber que não existia comitê algum instalado.

Foram também realizadas entrevistas semiestruturadas durante a realização do XIII ENCOB - Encontro Nacional de Comitês de Bacias Hidrográficas, realizado na cidade de São Luís - MA, com membros dos seguintes comitês: do Rio São Francisco (Domínio Federal), dos Rios Guandu, da Guarda e Guandu Mirim (Domínio Estadual - RJ), do Rio Piratinim (Domínio Estadual - RS), do Rio do Peixe (Domínio Estadual- SC), das Bacias Hidrográficas Metropolitanas do Ceará (Domínio Estadual - CE), do rio Capibaribe (Domínio Estadual-PE), dos rios dos Rios Piracicaba, Capivari e Jundiaí (Domínio Federal) e dos rios Turvo/Grande (Domínio Federal) no intuito de avaliar, também, na percepção desses comitês, a efetividade deste modelo.

Por fim, foram aplicados questionários com quatorze comitês existentes nos estados da Bahia, Sergipe, Alagoas, Pernambuco, Paraíba, Rio Grande do Norte, Ceará e Piauí. A análise dos dados e a confrontação das informações obtidas na pesquisa com o referencial teórico são apresentadas no tópico a seguir.

\section{RESULTADOS E ANÁLISES}

Esta seção tem por objetivo apresentar uma análise dos dados da pesquisa e os principais resultados obtidos com o presente estudo. Inicialmente são tratadas as questões que referenciam os fatores técnicos, políticos e financeiros, e em seguida, são discutidas questões que procuram avaliar a efetividade deste modelo de gestão.

Ao analisar o resultado dos dados obtidos através da pesquisa, constata-se que os aspectos técnicos levantados por Gutiérrez (2006) aparentemente estão sendo administrados pelos comitês. Fatores como capacidade de argumentação, motivação e capacidade técnica não são fatores restritivos na implementação do modelo, apesar de ficar comprovado que a maior parte dos comitês não tem uma política de capacitação efetivamente implementada. Esta capacitação seria de fundamental importância para a eficiência dos comitês segundo autores como Gutiérrez (2006), Lanna (2010), Lemos (2011) e ratificados por vários entrevistados dos órgãos estaduais responsáveis pela implementação do modelo.

Já com relação aos aspectos políticos, os dados demonstram que, de uma maneira geral, nos comitês não há atores dominantes. Sempre prevalece um equilíbrio na participação 
dos representantes dos três segmentos, com uma leve inclinação para uma dominação por parte dos representantes do poder público e dos usuários em detrimento dos representantes da sociedade civil. A maioria (79\%) acredita que as decisões do comitê não sofrem interferência externa, nem política e nem econômica. São decisões técnicas que sustentam o seu funcionamento, mantendo-o protegido. Os comitês, de uma maneira geral, mantêm uma efetiva relação com os outros segmentos que compõem o Sistema Nacional de Recursos Hídricos, porém a grande maioria acredita existir um distanciamento entre a ANA e os comitês. Foi possível constatar também, que os governos geralmente apoiam as decisões dos comitês, apesar de ficarem registrados alguns casos em que o governo ignorou as decisões desses colegiados.

Sessenta e quatro por cento dos pesquisados considera que a população residente nos municípios componentes da bacia se preocupa com as questões ligadas a água. No entanto, a grande maioria dos pesquisados informa que não existe um reconhecimento por parte da população, do papel do comitê. Nesse sentido, pode-se inferir que esta população ainda não tomou pleno conhecimento desse processo de gestão de recursos hídricos por comitês de bacias hidrográficas e nem sequer conhece os seus principais atores, ou seja, o envolvimento da sociedade no processo de implementação deste modelo ainda está em uma fase muito incipiente.

Neste sentido, pode-se inferir também que existe certa deficiência na sustentação política do modelo, inicialmente pelo distanciamento da ANA no processo de implantação dos comitês, seguido pelo não reconhecimento, por parte da população da bacia, do papel dos comitês, e finalmente por alguns posicionamentos do governo, exercendo certo domínio sobre os outros segmentos que compõem os colegiados, inclusive em alguns casos, chegando até a ignorar as decisões tomadas por estes.

E, finalmente, em relação aos fatores financeiros, que segundo Gutiérrez (2006), influenciam o processo de implementação da gestão de recursos hídricos por comitês de bacias hidrográficas, os dados demonstram que a quase totalidade dos comitês analisados não têm sustentabilidade financeira. A única exceção está no estado do Ceará que já iniciou o processo de cobrança pelo uso da água, apesar de os comitês deste estado não participarem do planejamento da utilização deste recurso. Esta cobrança pelo uso da água foi estabelecida sob a forma de tarifas a serem arrecadadas pela Companhia de Gestão dos Recursos Hídricos COGERH, pelo Decreto estadual $n^{\circ}$ 24.264, de 12 de novembro de 1996, complementado pela Deliberação no 3/97 do Conselho Estadual de Recursos Hídricos - CONERH.

O fato de o estado do Ceará ser o único do nordeste que já iniciou o processo da 
cobrança pelo uso da água, aparentemente demonstraria que este estado está em um estágio mais avançado na implementação da política de recursos hídricos. Porém, o modelo adotado no Ceará tem características que diferem do que é preconizado pela Lei $n^{0}$ 9.433/97. No Ceará, os recursos arrecadados não são geridos pelos comitês. A COGERH é que decide sobre a destinação destes recursos, situação que é bastante questionada pela maioria dos membros dos comitês existentes. Todo o processo de implantação da cobrança pelo uso da água deve ser discutido e aprovado pelo comitê, e tem como objetivo estimular o uso racional da água e gerar recursos financeiros para investimentos na recuperação e preservação dos mananciais das bacias.

$\mathrm{Na}$ realidade, a maioria dos comitês ainda não iniciou a cobrança pelo uso da água, não dispõe de Agências de Água, não faz captação de recursos através de outras fontes, sendo seu funcionamento garantido, com muitas restrições, pelos governos estaduais através dos órgãos responsáveis pela implantação da política de recursos hídricos. Cinquenta e sete por cento desses comitês estão sem os respectivos planos de bacias elaborados e $64 \%$ não tem estrutura física satisfatória para o seu funcionamento, entre outros aspectos que revelam a sua incipiência.

Considerando que a cobrança pelo uso da água é o principal pilar de sustentação financeira do atual modelo de gestão de recursos hídricos por bacias hidrográficas, quando esta não está efetivada acontece uma forte limitação na implementação deste modelo, como afirma Gutiérrez (2006, p. 110):

\begin{abstract}
Segundo o novo marco legal, a cobrança é central para o funcionamento dos comitês, na medida em que todos os gastos operativos, os estudos necessários e os projetos e ações aprovados pelo comitê deveriam ser financiados mediante ela. Daí que a nãoimplementação da cobrança, na maioria dos comitês brasileiros, se traduza, na prática, numa forte limitação da sua capacidade de ação.
\end{abstract}

Por fim, quando se avaliou a efetividade deste modelo de gestão a partir da sua concepção estabelecida pela Lei das Águas, observou-se que, dos comitês entrevistados, a maioria considera que a lei que criou o modelo é clara. No entanto, nas observações realizadas durante esta pesquisa, foi possível constatar o desconhecimento, por parte dos comitês de bacias e de seus membros, do conteúdo integral desta lei e do que ela preconiza. A maioria destes acredita que o comitê de bacia é apenas um fórum no qual se dirimem todos os 
conflitos relativos aos usos dos recursos hídricos.

Já em relação ao entendimento dos integrantes sobre se o papel do comitê de bacia na gestão de recursos hídricos vem sendo cumprido conforme a lei que o criou, pouco mais da metade (64\%) afirma que sim, e 36\% considera que não. Neste ponto vale ressaltar que os planos de bacias de $57 \%$ dos comitês pesquisados ainda não foram construídos, o que significa que a lei não está sendo cumprida.

Observou-se, também, que todos os entrevistados entendem que o modelo descentralizado e participativo é um fator propulsor da efetividade da gestão dos recursos hídricos por comitês de bacias. Possivelmente isso foi apontado, porque, com a descentralização, pode-se também ter acesso ao "conhecimento disponível em nível local (incluindo o conhecimento prático, leigo e nativo)" com isso, em tese, permite-se que experiências locais, não disponíveis em outras áreas e regiões, sejam incorporadas (RIBOT, 1999 Apud LEMOS, 2010, p. 191).

No entanto, há a percepção de Barros (2000), segundo a qual o processo de gestão descentralizada e participativa previsto na Lei $n^{\circ}$ 9.433/97 é dificultado porque grande parte da população ainda acredita na disponibilidade infinita da água, aliado ao fato que as diversas instâncias governamentais estão historicamente acostumadas com a administração centralizada. São os governos estaduais os detentores do poder de criação dos comitês de bacias estaduais, ou seja, bacias cujo rio principal não atravessa as fronteiras do estado. Legalmente são eles que criam esses comitês e esta vinculação faz com que o sistema fique a mercê da vontade política dos governantes estaduais. De fato, nesse sentido, várias situações podem ser observadas. Enquanto em alguns estados como São Paulo, Minas Gerais e Rio de Janeiro os comitês já foram criados e estão em pleno funcionamento, muitos inclusive já arrecadando com a cobrança pelo uso da água, em outros estados como, por exemplo, o Maranhão, nenhum comitê foi criado.

Quanto à dimensão da participação, é de se supor que, como a Bacia Hidrográfica é a unidade de gestão, as decisões sejam tomadas pelos que estão mais próximos dos problemas daquela bacia, ainda que esta bacia extrapole os limites de um ou mais municípios ou até os limites de um ou mais estados. Todos aqueles que usufruem desta bacia têm direito de participar da sua gestão. Porém, o que se observa nesses comitês é que ainda não há infraestrutura necessária para o exercício pleno desta participação, como também a população não está capacitada para esta participação. 


\section{CONSIDERAÇÕES FINAIS}

Este artigo buscou entender o efetivo estágio de implementação do atual modelo de gestão de recursos hídricos por comitês de bacias hidrográficas nos estados do nordeste, analisando os comitês localizados nos estados da Bahia, Sergipe, Alagoas, Pernambuco, Paraíba, Rio Grande do Norte, Ceará e Piauí, no exercício de suas competências formais e a partir da análise de fatores técnicos, fatores políticos e fatores financeiros, partindo dos dois pilares que estruturam este modelo de gestão. O que este estudo mostra é que há ainda algumas resistências dos estados da federação em praticar a descentralização na sua plenitude. Na região nordeste nem todos os comitês foram criados e há um estado que não tem comitê algum. Como os governos estaduais e governo federal são os detentores legais do direito de uma iniciativa e decisão de criação dos comitês estaduais e federais respectivamente há, ainda, uma dependência do poder público para iniciar este processo.

O país tem realidades diferentes. Há estados como Minas Gerais e São Paulo nos quais houve decisão política dos seus governantes e os comitês foram criados. Em outros já criados, ou não iniciaram a implementação dos comitês, ou não o fizeram de forma plena. $\mathrm{Ou}$ ainda, implantaram os comitês com distorções com relação ao que a lei preconiza, ainda, centralizando as decisões para o seu funcionamento nos governos. Isso foi observado, por exemplo, no estado da Bahia, onde o poder público não garante assento aos membros dos comitês de bacias no Conselho Estadual de Recursos Hídricos, e no estado do Ceará, onde os recursos arrecadados com a cobrança pelo uso da água são gastos sem a participação dos comitês na decisão. Essas distorções podem gerar uma perda de credibilidade por parte da sociedade e desestímulo à participação. Isso foi percebido durante as entrevistas com os responsáveis dos órgãos estaduais envolvidos na implementação desta política, assim como em reuniões que esses pesquisadores participaram, além da consulta às atas de algumas reuniões dos comitês do Recôncavo Norte e Inhambupe, no estado da Bahia e do rio Sergipe.

É possível verificar que nos estados nos quais o modelo foi efetivamente implementado, com instituição da cobrança pelo uso da água, com criação de Agência de Água, desenvolvendo-se de forma autônoma, o modelo tem sido efetivo. Por exemplo, os comitês da Bacia Hidrográfica do Rio São Francisco e os Comitês das Bacias Hidrográficas dos Rios Piracicaba, Capivari e Jundiaí e da Bacia Hidrográfica dos Rios Piracicaba e Jaguari, estão cumprindo o seu papel, dando respostas à sociedade, minimizando os conflitos nesta seara que é tão complexa, que envolve tantos interesses, quer sejam ambientais, econômicos e políticos. Nesses casos, o modelo tem funcionado adequadamente. 
O segundo pilar, que é o processo participativo, tem, como foi destacado, aspectos positivos, ainda que, de certa forma, intangíveis. Ampliam a legitimidade das escolhas públicas fortalecendo o que se entende por democracia e, ainda, melhorando as condições de governabilidade e governança. No entanto, a participação nas decisões administrativas, ou seja, a gestão participativa tem sido tema pouco explorado e discutido, de modo que se possa identificar experiências que tenham resultado em ganhos efetivos. De modo geral, a maior ênfase das discussões sobre processos participativos tem sido sobre aqueles que se dão por meio da atuação de sociedades civis organizadas, ações populares ou conselhos, do que, propriamente acerca de experiências de gestão participativa.

Além do mais, nem sempre a participação dos agentes sociais nos processos decisórios ocorre com a mesma intensidade, quer seja pela a assimetria de conhecimento dessas representações com assento nos Comitês de Bacia, quer seja pela ausência de competência técnica para tomar determinadas decisões. Esses são alguns dos entraves que comprometem a eficiência deste modelo de gestão assentado em processos participativos, que são complexos e exigem muito esforço para a sua efetividade e manutenção.

Com relação à análise do estágio de implementação e de funcionamento dos comitês, destacando-se os fatores técnicos, políticos e financeiros, a pesquisa revela uma realidade singular. Observou-se, de fato, que os comitês de bacia se encontram em diferentes níveis de desenvolvimento nas diversas regiões do país nas quais estão implantados. No caso deste trabalho, foi destacada a região nordeste, objeto do estudo. Há uma gradação no envolvimento (interesse) dos agentes sociais, mais ou menos investimento para sua implantação, fatores que variam conforme a bacia, que está imersa em uma cultura, região e economia determinada, o que significa dizer que o fator histórico-cultural contribui fortemente para a definição desse mosaico.

Nesse sentido, na implementação desta política constata-se que regiões de maior desenvolvimento socioeconômico, como as regiões sul e sudeste, aparentemente tiveram menos dificuldade do que as regiões norte e nordeste. Como não existe pressão por parte da sociedade, muitas vezes até por desconhecimento do modelo, os governos estaduais destas regiões não avançam na implementação desta política. E isso acontece também no âmbito das bacias federais. A pesquisa revela que a maior parte dos comitês federais criados está nas regiões sul e sudeste. Ao que parece, o sudeste e sul conseguiram equacionar melhor este aspecto quando comparados com as outras regiões do país e, neste caso, com a região nordeste.

Em entrevistas com representantes dos órgãos estaduais de vários estados do 
nordeste foi relatado que a ANA deixava a entender que não tinha interesse em criar os comitês federais daqueles estados. Um entrevistado do estado de Alagoas, por exemplo, relatou que a ANA priorizava outras bacias, que tivesse maior repercussão nacional. Já o presidente do Comitê do Rio São Francisco, quando perguntado por que a ANA não criava os comitês federais da região nordeste, afirmou que caberia à sociedade iniciar o processo, ou seja, falta pressão por parte da sociedade. Segundo ele, se isso acontecesse a ANA daria todo o apoio necessário. O fato é que nos estados do nordeste, com exceção das grandes bacias, poucos comitês de rios de domínio federal foram criados.

Enfim, o modelo foi idealizado para funcionar de forma autônoma, mas os comitês ainda não adquiriram esta autonomia. São os recursos oriundos da cobrança pelo uso da água que lhes darão condições para que eles se desenvolvam sem depender dos governos dos estados, nem financeiramente, nem politicamente. Com esta autonomia, o poder de decisão passa a ser da comunidade que vive nos municípios integrantes daquela determinada bacia. É a comunidade que vai decidir como utilizar os recursos arrecadados pela cobrança do uso da água. Entretanto, como a cobrança pelo uso da água é condição indispensável para a sustentabilidade financeira e, em consequência, autonomia, e como esta cobrança ainda não foi instituída nesses comitês, esta autonomia fica impossível de ser exercida.

Ao final deste trabalho, algumas pistas para novos estudos podem ser evidenciadas. Uma delas consiste em uma discussão mais ampla sobre as condições de implantação deste modelo e a sua adequação à cultura política e administrativa brasileira, ainda arraigada à centralização do poder. Um desdobramento dessa possibilidade é a discussão sobre as resistências para a cobrança pelo uso da água e a consequente criação das Agências de Água. Esses aspectos relacionam-se com a questão da autonomia do modelo. Para que essa autonomia possa ser garantida, os recursos arrecadados devem ser alocados para ações e projetos a serem executados em suas respectivas bacias, aprovados nos comitês, além de garantir o pagamento dos gastos operativos do funcionamento destes. Enquanto esta cobrança não ocorre, cabe ao poder público, através dos órgãos responsáveis pela implementação desta política, promover a mobilização e garantir toda a logística necessária para o funcionamento da participação das comunidades que vivem nos municípios integrantes daquela determinada bacia. Com isso, mantem-se a vinculação com o governo em uma condição de quase subordinação.

\section{REFERÊNCIAS}


ABERS, R. N. Água e política: atores, instituições e poder nos organismos colegiados de ABERS, R. N.; KECK, M. Comitês de Bacia no Brasil, uma abordagem política no estudo da participação social. R. B. Estudos Urbanos e Regionais, Campinas, v. 6, n. 1, p. 55-68, 2004.

ABERS, R. N.; JORGE, K. D. Descentralização da gestão da água: por que os comitês de bacia estão sendo criados? Ambiente \& Sociedade, v. VIII, n. 2, p. 1-26, 2005. AGÊNCIA NACIONAL DE ÁGUAS-ANA. Institucional (Missão). Disponível em: $<$ http://www2.ana.gov.br/Paginas/institucional/SobreaAna/abaservinter1.aspx $>$. Acesso em: 10 ago. 2012.

ARGENTINA. Ley n ${ }^{\circ}$ 3.295/00, de 09/02/2010. Ley de Gestión Ambiental Del Agua de la Ciudad Autónoma de Buenos Aires. Disponível em:

$<$ http://www.cedom.gov.ar/es/legislacion/normas/leyes/ley3295.html>. Acesso em: 26 abr. 2013.

BARROS, A. B. de. Na gestão de Bacias Hidrográficas é preciso respeitar o espírito da Lei no 9.433/97. Águas do Brasil: Revista (SRH), n. 2, p. 38-39, 2000.

BORSOI, Z. M. F; TORRES, S. D. A. A política de recursos hídricos no Brasil. Revista do BNDES, Rio de Janeiro, v. 4, n. 8, p. 143-166, 1997.

BRASIL. MINISTÉRIO DO MEIO AMBIENTE. Sistema Nacional de Gerenciamento de Recursos Hídricos. Disponível em:

$<$ http://www.mma.gov.br/sitio/index.php?ido=conteudo.monta\&idEstrutura=161\&idConteud o=9515\&idMenu=10197>. Acesso em: 16 mai. 2012.

CAMPOS, V, N, G.; FRACALANZA, A. P. Governança de águas no Brasil: conflitos pela apropriação da água e a busca da integração como consenso. Revista Ambiente \& Sociedade, v. 18, n. 2, p. 365-382, jul/dez. 2010.

CASTRO, J. E. La privatización de los servicios de agua y saneamiento en América Latina. Nueva Sociedad, n. 207, p. 93-112, 2007.

COASE, R. H. The nature of the firm. In: WILLIAMSON, O. ; WINTER, S. (Orgs.). The nature f the firm. New York, Oxford: Oxford University Press, 1991. p. 18-33.

DAGNINO, E.. Sociedade civil, participação e cidadania: de que estamos falando? In: MATO, D. (Coord.). Políticas de ciudadanía y sociedad civil em tiempos de globalización. Caracas: Faces/ Universidad Central de Venezuela, 2004.

DIAS, T. F.; BARROS, H. de. Gestão de recursos hídricos: uma olhar para visões da cobrança pelo uso da água a partir dos membros do Comitê de Bacia Hidrográfica do Rio Pirapama-PE. Encontro de Administração Pública e Governança. Anais... Salvador, 2008. 
FADUL, É. Limites e contradições de um modelo decisório inovador. Revista O\&S, v. 6, n. 15, p. 149-158, 1999.

FADUL, É. et al. Produção Científica em Gestão de Recursos Hídricos no Brasil no período de 2002 a 2011: uma análise da sua contribuição para o setor. Encontro de Administração Pública e Governo. Anais... Salvador, 2012.

FLORES, R. K. O discurso como estratégia de luta contra a mercantilização da água. In: X Colóquio Internacional sobre Poder Local, Anais... Salvador, 2006.

FLORES, R. K.; MISOCZKY, M. C. Participação no gerenciamento de bacia hidrográfica: o caso do Comitê Lago Guaíba. Revista de Administração Pública, v. 42, n. 1, p. 109-131, 2008 .

FLORES, R. K.; MISOCZKY, M. C. Dos antagonismos na apropriação capitalista da água à sua concepção como bem comum. Organizações \& Sociedade, v. 22, p. 237-250, 2015. FREY, K. Políticas públicas: um debate conceitual e reflexões referentes à prática da análise de políticas públicas no Brasil. Planejamento e Políticas Públicas (IPEA), v. 21, p. 211-259, 2000.

GUTIÉRREZ, R. A. Comitê Gravataí: Gestão participativa da água no Rio Grande do sul. Lua Nova, n. 69, p. 79-121, 2006.

HARDIN, Garrett. The tragedy of the commons. Science, v. 162, n. 13, p. 12431248, 1968.

HESPANHOL, I. Potencial de reuso de água no Brasil: agricultura, indústria, municípios, recarga de aquíferos. Bahia Análise \& Dados. Salvador, v. 13, n. Especial, p. 411-437, 2003. JACOBI, P. R. Governança da água no Brasil. In: RIBEIRO, W. C. (Org.). Governança da água no Brasil: uma visão interdisciplinar. São Paulo: Annablume Editora, 2009. p. 1-38. JACOBI, P. R. Participação na Gestão Ambiental no Brasil: os comitês de bacias hidrográficas e o desafio de fortalecimento de espaços públicos colegiados. In: ALIMONDA, H. (Org.). Los tormentos de la materia: aportes para una ecología política latinoamericana. Buenos Aires: CLACSO, 2006. p. 169-194.

LANNA, A. E. L. A inserção da gestão das águas na gestão ambiental. In: MUÑOZ, H. (Org.). Interfaces da gestão de recursos hídricos: desafios da lei das águas de 1997. Brasília: Secretaria de Recursos Hídricos, 2000.

LANNA, A. E. L. O desmonte do Sistema Estadual de Recursos Hídricos. 2010.

Disponível em: $<$ http://www.creadigital.com.br/rs/edulanna?txt=3077363130>. Acesso em: 24 jan. 2016.

LEMOS, M. C. Informação Técnica e Gestão Participativa de Bacias Hidrográficas no Brasil. 
In: ABERS, R. N. (Org.). Água e política: atores, instituições e poder nos organismos colegiados de bacia hidrográfica no Brasil. São Paulo: Annablume, 2010. p. 191-209.

MARTINS, R. C. Uso e gestão dos recursos hídricos no Brasil: desafios teóricos e políticoinstitucionais. São Carlos: RiMa, 2003.

MARTINS, R. C. A construção social da economia política da água. Sociologia (Lisboa), v. 2013, p. 111-130, 2013.

MÉSZÁROS, I. Para além do capital: rumo a uma teoria da transição. São Paulo: Boitempo, 2002.

NOVAES, R. C. Cooperação e conflito nas águas da Bacia do Rio Paraíba do Sul: limites e possibilidades de Gestão Integrada no "Trecho Paulista". Tese Doutorado em Ciência Ambiental.São Paulo: Universidade de São Paulo, 2006.

OSTROM, E. Governing the commons: the evolution of institutions for collective action. Nova York: Cambrige University Press, 2008.

OLSON, M. The logic of collective action: public goods and the theory of groupsBoston: Harvard UP, 1971.

PORTO, M. F. A.; PORTO, R. L. Gestão de bacias hidrográficas. Estudos Avançados, v.22, n.63, p.43-60, 2008.

RIO, G. A. P. do; MOURA, V. P. ; SALES, A.V.S. Gestão de recursos hídricos: aspectos metodológicos. In: Encontro da Associação Nacional de Pós-Graduação e Pesquisa em Ambiente e Sociedade, 2., 2004, São Paulo. Anais... 2004.

SANTOS, M. E. P. As Águas como direito e como commodity - uma contradição em termos? RDE - Revista de Desenvolvimento Econômico, v. 4, n. 6, p. 60-70, 2002.

SANTOS, M. E. P.; MORAES, L. R. S.; ROSSI, R. A. Água como direito e como mercadoria: os desafios da política. Bahia Analise \& Dados, v. 23, p. 437-459, 2013. SILVA, D. D.; PRUSKI, F. F. (Eds.). Gestão de recursos hídricos: aspectos legais, econômicos, administrativos e sociais. Brasília, DF: Secretaria de Recursos Hídricos; Viçosa, MG: Universidade Federal de Viçosa; Porto Alegre: Associação Brasileira de recursos Hídricos, 2000.

TIGRE, Paulo Bastos. 2006. Gestão da inovação: a economia da tecnologia no Brasil. Rio de Janeiro: Editora Elsevier.

TUCCI, C. E. M.; HESPANHOL, I.; CORDEIRO NETTO, O. de M. 2001. Gestão da água no Brasil. Brasília: Unesco, 156p. Disponível em:

$<$ http://www.crmariocovas.sp.gov.br/pdf/pol/gestao_agua.pdf $>$. Acesso em: 1 fev, 2016. 